\title{
Law and Unified Social Theory
}

\section{ROBERT COOTER*}

An economist who talks about unified theory to lawyers and social scientists gets welcomed rather like the British expedition to Afghanistan in 1840. The Afghanistanis preferred to fight rather than join the British empire, and many social scientists are similarly disposed towards the economics empire. Like the nineteenth-century British, however, economics imperialism has succeeded remarkably. Economic models of rational behaviour have affected all the social sciences in the last thirty years, as well as history, philosophy, and law. Everyone in social science, whether friend or foe of economics, should want to understand its success.

In this essay, I will try to explain the success of the economic analysis of law, but I will not merely praise the subject. My own feelings are too complicated for that. Like others in my generation of undergraduates, I had a special aversion to materialism. Microeconomics concerns the efficiency of markets, but I was more interested in the majesty of law, the struggle of politics, and the deciphering of culture. My explanation of the successes of economics will reveal limits in models of rational behaviour that insulate economics from psychology and sociology. The correction of these structural deficiencies would unify behavioural theory and overcome limitations in the economic analysis of law.

\section{PROGRESS IN ECONOMIC ANALYSIS OF LAW ${ }^{1}$}

Until recently, law confined the use of economics to antitrust, regulated industries, tax, and monetary damages. Law obviously needed economics to answer such questions as, 'What is the market share of an alleged monopolist?', 'Will price controls reduce the availability of automobile insurance?', 'Do the rich pay the capital gains tax?', and 'How much future income do children lose from their father's death?' Beginning in the 1960s, however, the breadth of the economic analysis of law expanded remarkably by its application to property, contracts, torts, crimes, procedure, and constitutional law. Economic analysis addressed new questions such as, 'Will private

* Professor of Law, School of Law (Boalt Hall) University of California, Berkeley, California 94720, United States of America 
ownership of the electromagnetic spectrum encourage its efficient use?', 'What damage remedy for breach causes the most reliance on contracts?', 'Does strict liability for consumer product injuries cause excessive precaution by manufacturers?', 'Will harsher punishments deter violent crime?', and 'Does bicameralism increase the discretionary power of courts?' By addressing such questions, economics changed American legal scholarship. At least one economist is on the faculty of every top law school in the United States of America; some law faculties in western Europe also include an economist. Joint degree programmes in law and economics exist in many prominent American universities. Law and economics associations meet annually in Europe, Canada, and the United States of America. Law reviews publish many articles using the economic approach and some journals are devoted exclusively to law and economics. Many law school classes in the United States now include a summary of the economic analysis of the class's subject. An exhaustive study recently found that the major American law journals cite articles using the economic approach more than articles using any other approach. ${ }^{2}$ In 1991 and 1992, the Nobel prizes in economics were awarded to Ronald Coase and Gary Becker, two pioneers in the economic analysis of law.

Outside the universities, economic analysis affected law and public policy in various ways. Economic analysis provided the intellectual foundation for the deregulation movement, which dramatically changed the law for regulated industries in several countries. A committee created by the United States Congress in 1984 to reform criminal sentencing in the federal courts (the U.S. Sentencing Commission) explicitly used the findings of law and economics to reach some of its results. Several law and economics scholars have become federal appellate judges, including Richard A. Posner, Frank Easterbrook, Robert Bork, and Stephen Breyer, whose confirmation hearing for the Supreme Court proceeds as I write.

\section{WHY DID THE ECONOMIC ANALYSIS OF LAW SUCCEED?}

The economic analysis succeeded more than its most optimistic founders expected. Why? Like the rabbit in Australia, economics found a vacant niche in the intellectual ecology and rapidly filled it. To understand the niche, consider this classical definition: 'A law is an obligation backed by a state sanction.' Lawmakers and adjudicators often ask, 'How will this sanction affect behaviour?' For example, if the manufacturer of a defective product faces liability for consequential damages, what will happen to the product's safety and price?

Lawyers answered such questions in 1960 in much the same way as in 60 $\mathrm{BC}$, by consulting intuition and any available facts. A scientific theory to predict the effects of sanctions upon behaviour, which lawyers lacked, developed from economics after 1960 . Just as laws impose sanctions on acts, 
markets charge prices for commodities. Economists developed price theory, which is mathematically precise and empirically confirmed, to predict how people respond to prices. To economists, sanctions look like prices, because both are tariffs on behaviour. Presumably, people respond to heavier sanctions much like they response to higher prices. Adapting price theory to law allowed economists to predict how people respond to sanctions. To illustrate, suppose that a manufacturer knows that his product will sometimes injure consumers. How safe will he make the product? The answer depends upon the actual cost of safety, which depends in turn upon facts about design and manufacture. In addition, the answer depends upon the 'implicit price' paid by the producer for injuries to consumers, including liability. The producer will need the help of lawyers and other experts to estimate the implicit price. After obtaining the needed information, the rational producer will compare the cost of safety and the implicit price of accidents. To maximize profits, the producer will adjust safety until the actual cost of additional safety equals the implicit price of additional accidents.

I have been discussing sanctions as if they were fixed prices. Some prices, however, are negotiated rather than fixed. Understanding negotiation requires strategic theory. In American football, a player often runs around the right side as a decoy to fool the other team while the player carrying the ball runs around the left side. In contrast, a mountain climber never starts up the south slope as a decoy to fool the mountain while the main party climbs up the north slope. Football is strategic and mountain climbing is non-strategic. In strategic games, each player forms his or her strategy on the assumption that other players form their strategies by anticipating what he or she will do. In non-strategic games, each player assumes that other players form their strategies without anticipating what he or she will do.

Economists apply price theory to law by treating sanctions as prices. Price theory usually assumes that people behave non-strategically. Specifically, each participant in a competitive market expects that his or her own buying and selling will not affect prices. In contrast, game theory analyses strategic behaviour. The rules of a game prescribe the moves that players may make, and the theory of games predicts how people will change their moves in response to changes in rules. Like rules of games, rules of law prescribe how people may interact with each other. When people interact in the shadow of the law, their behaviour often depends upon what each person thinks the others will do. Consequently, rules of law are like rules of games for purposes of economic analysis. Whether people behave strategically or non-strategically often depends upon the number of players in the game. In games with many players, each one may assume that his or her behaviour alone cannot affect what others do, as in a perfectly competitive model. In games that pit a few players against each other, each one may assume that his or her behaviour affects what others do. For example, the two parties in settlement bargaining try to anticipate each other's offers, the principal in a fiduciary relationship drafts a contract that anticipates the agent's reaction, and those 
who create a nuisance on their property may anticipate their neighbours' response.

The original applications of price theory to law generally treated sanctions as competitive prices, so the models were non-strategic. To illustrate, each criminal assumes that his or her crimes cannot affect the state's schedule of criminal sanctions, each consumer assumes that his or her precaution will not affect the probability of a product's being defective, and each commuter assumes that his or her decision to drive the to work will not affect the decisions of other commuters to drive.

Non-strategic behaviour is simpler to analyse than strategic behaviour. Early in its development, the economic analysis of law found a technique for analysing strategic behaviour as if it were non-strategic. The most famous proposition in the economic analysis of law, the Coase Theorem, asserts that bargaining succeeds so long as 'transaction costs' are low. Thus, the Coase Theorem treats strategic behaviour as a transaction cost. Treating strategic behaviour as a cost facilitated the rapid assimilation of price theory into law. In reality, strategic behaviour does not resemble the cost of oranges, haircuts, or any other good. Calling strategic behaviour a 'cost' postpones analysing it. ${ }^{3}$ Game theorists are reworking the economic analysis of law under the assumption that people behave strategically, just as they transformed the study of industrial organization in the $1980 \mathrm{~s} .{ }^{4}$ To illustrate, we now understand better how settlement offers by defendants screen and sort plaintiffs according to the strength of their case. Plaintiffs with strong cases reject a settlement offer and proceed to trial; plaintiffs with moderate cases accept a settlement if offered and go to trial otherwise; plaintiffs with weak cases accept a settlement if offered and drop the case otherwise. The rational defendant uses these facts to compute the settlement strategy that minimizes his or her costs.

Generalizing, we can say that economics provides a behavioural theory to predict how people respond to changes in laws. At the simplest level, where people respond to the sanctions imposed by the state, but not to each other, price theory predicts how changes in sanctions change behaviour. At a more complex level, where people respond to the state and each other, game theory predicts how changes in laws change behaviour. These theories surpass intuition just as science surpasses common sense. In addition to a scientific theory of behaviour, economics provides a useful normative standard for evaluating law and policy. To make public policy, judges and other lawmakers need to know its effects on important values. A member of the California Supreme Court recently presided over a pretend court ('moot court') for law students. After listening to an hour of technical legal arguments, he banged his fist on the table and said, 'What are the policy arguments? This is the highest court in California. I want to know the policy arguments!' To make public policy, judges and other lawmakers need to know its effects on important values. Economics predicts the effects of policies on efficiency. Public officials never publicly advocate wasting money, 
so efficiency is always relevant to policy debates. Besides efficiency, economics also predicts the effects of policies on distribution. More than other social scientists, economists understand how laws affect the distribution of income and wealth across classes and groups. For example, in one of its earliest applications to public policy, economics predicted who really bears the burden of alternative taxes. In general, economics predicts how laws affect efficiency and distribution, which are two of the most important policy values for lawmakers.

\section{X-RAY VISION VERSUS PERIPHERAL VISION}

When I described the successful institutionalization of the economic analysis of law, I did not mention that many law professors in the United States of America say that economics no longer dominates the runway of intellectual fashion as it once did. Some professors even talk about a 'crisis' in the subject. ${ }^{5} \mathrm{~A}$ radio commentator allegedly summarized the evening news by saying, 'The political crisis in Germany is serious but not desperate, and the political crisis in Italy is desperate but not serious.' The alleged 'crisis' in law and economics is not desperate, because its institutionalization continues unabated. Nevertheless, deficiencies in the subject are serious enough to impair the realization of its full potential.

One of the most thoughtful commentators on the economic analysis of law, Robert Ellickson, believes that theory has outrun fact in this field. ${ }^{6}$ Ellickson thinks that the economic analysis of law creates too many models and tests too few of them. His remedy is a dose of empirical research motivated by insights more than models, a method exemplified in the 'law and society' movement. My approach in this lecture complements Ellickson's. Theory explains by narrowing attention to recognized causes. Consequently an incomplete theory may prevent a researcher from perceiving all the facts. The economic analysis of law has X-ray vision, not peripheral vision. I believe that incompleteness in economic theory prevents researchers from perceiving facts that psychologists and sociologists regard as central to law. In the next section I explain why.

\section{CORE}

Economists usually assume that people maximize something - consumers maximize utility, firms maximize profits, politicians maximize votes, bureaucracies maximize revenues, charities maximize social welfare, and so forth. Theories that assume maximizing have proven useful in predicting behaviour. Economists often say that these models succeed because maximization models rationality and most people are rational. Evaluating this claim requires an understanding of economic rationality. Different people 
want different things, such as wealth, power, fame, love, virtue or happiness. One conception of rationality holds that rational persons can rank alternatives according to the extent that they give them what they want. ${ }^{7}$ Rationality further requires choosing the highest ranking alternative that is available. It would be irrational to do worse by your own standards when you can do better.

Choosing the highest ranking alternative that is available can be described mathematically as maximizing. Just as the person ranks alternatives from worse to better, so the real numbers can be ranked from small to large. To represent the ranking of alternatives mathematically, create a 'utility function' to associate better alternatives with larger numbers. Next, partition the set of alternatives into the available alternatives and the unavailable alternatives. Represent the partition mathematically as a constraint upon the utility function. Choosing the best available alternative corresponds to maximizing the utility function subject to the feasibility constraint. For example, the consumer who goes shopping probably thinks of him or herself as trying to get as much of what he or she wants as can be afforded, and that behaviour is represented as maximizing his or her utility subject to his or her budget constraint.

The maximum of a function is often located where its derivative equals zero, or, in economic jargon, where costs and benefits equalize at the margin. Economists realized this fact when they joined utilitarianism and calculus in the late nineteenth century. The result was the 'marginalist revolution' which gave economic theory its modern form. Subsequent developments have built upon the late nineteenth-century foundations without discarding them. It seems that the marginalists got the foundations right, whereas attempts at mathematical economics before the marginalists went nowhere.

Maximizing suggests that an agent calculates and tries to do the very best that he or she can. Much of what people do that lands them in court, however, is uncalculated or even irrational. Think of rationality as a continuum with irrationality at one end and hyper-rationality at the other. Market competition extracts a harsh price for diminished rationality. Consequently, highly competitive markets approach hyper-rationality, as demonstrated, for example, by applications of the efficient market hypothesis to stock markets. At the other end, some torts and crimes occur when the injurer's rationality has diminished so far that the behaviour seems irrational. Economics has traditionally focused on high levels of rationality. Economic scholars now debate vigorously how to model diminished rationality.

Turning to the second concept in the core of economic theory, no habit of thought is so deeply ingrained among economists as the urge to characterize each social phenomenon as an equilibrium in the interaction of maximizing actors. An equilibrium is a pattern of interaction that persists unless disturbed by outside forces. An equilibrium is stable if the system tends towards it when out of equilibrium. To illustrate, the snow pack in a mountain's bowl is in stable equilibrium, whereas the snow pack on the 
mountain's side is unstable. Economists usually assume that interactions tend towards a stable equilibrium, regardless of whether they occur in markets, elections, clubs, games, teams, corporations or marriages. An actor who tries to maximize and succeeds has no reason to change his or her behaviour. An interaction is an equilibrium when no one changes his behaviour. Consequently, an equilibrium exists when all actors maximize simultaneously. Conversely, an actor who tries to maximize and fails will change his or her behaviour. An interaction is not an equilibrium when someone changes his or her behaviour. In general, 'maximum' and 'equilibrium' are conceptually connected.

Social theorists often debate the relationship between the individual and society. Sociologists sometimes argue that the group is more than the sum of its parts, just as an animal is more than the sum of its head, torso, and limbs. Many sociologists believe in constructing theory from concepts like 'role' or 'class' that allegedly detach themselves from the goals of individuals and acquire their own life. At the other extreme, some psychologists practice methodological individualism, which reduces the study of groups to the behaviour of individuals. Unlike these approaches, an equilibrium does not detatch from individual behaviour or reduce to individual behaviour. Rather than detaching from individual goals, an equilibrium necessarily allows individuals to attain their goals. Rather than reducing to individual behaviour, an equilibrium cannot exist except in a group. For example, the market price depends upon the interaction of many buyers and sellers, who pursue their own self-interest. So does the unemployment rate or the inflation rate. Economists do not think that they can explain prices, unemployment or inflation until they construct a model of interacting individuals whose equilibrium accurately predicts the phenomenon in question.

'Equilibrium' describes a precise relationship between individuals and society, whereas popular metaphors often fail scrutiny. To illustrate, answering the question, 'Is society more than the sum of its parts?' requires comparing two numbers. What is to be added to arrive at the sum? The metaphor seems inappropriate because society lacks a metric. Similarly, comparing the society of bees to an organism makes sense, because genetic identity directs different bees in a hive towards the same goal, much as it directs different cells in a healthy body towards the same goal. However, comparing human society to an organism makes little sense, because people compete intensively with each other. Like bees, people perform roles, but unlike bees, people often subvert roles. Any social theory that omits competition among individuals leaves out the engine of change. Similarly, comparing the roles of bees to the functions performed by the parts of an automobile engine makes some sense, because bees perform their roles rigidly. A worker-bee does not change his mind and become a soldier-bee. In contrast, people commit to roles tentatively and perform them flexibly. A person may quit a job as a worker and become a soldier. A theory of human roles must explain what keeps people in them. 
A system headed towards a stable equilibrium reaches its destination unless diverted by outside forces. In markets and social life, outside forces often divert an interaction before it reaches equilibrium. Nevertheless, an equilibrium analysis makes sense methodologically. The simplest pattern of interaction to analyse is one that does not change. Tracing out the entire path of change is far more difficult. Microeconomic theories of growth, cycles, and disequilibria exist, but they have received little application to law so far. The basic approach in law is 'comparative statics' in which the equilibrium under one legal rule is compared to the equilibrium under another legal rule.

The core concepts of maximization and equilibrium concern social interaction, not specifically market interaction. These concepts could have been developed in political science or psychology, rather than in economics. Consequently, I think of these two concepts as part of the core of behavioural theory. Turning to the third concept in the core of economic theory, economists often evaluate an equilibrium according to its efficiency. A production process is said to be efficient if it is impossible to produce the same amount of output from fewer inputs, or it is impossible to produce more output from the same inputs. Another kind of efficiency, called 'Pareto efficiency' after its inventor, concerns the satisfaction of individual preferences. A particular situation is said to be Pareto efficient if it is impossible to change it so as to make at least one person better off (in his or her own estimation) without making another person worse off (again, in his or her own estimation). In general, Pareto efficiency asks whether someone can be made better off without making someone else worse off.

\section{DISTRIBUTION}

I will suggest, but not fully explain, why 'efficiency' is more central than 'distribution' to the economic analysis of law. Almost everyone agrees that the state should pursue policies efficiently rather than inefficiently, but many people disagree about policy goals concerning the distribution of income. Some people think that government should redistribute wealth from rich to poor for the sake of social justice, whereas other people think that government should avoid redistributing wealth. Like other people, economists disagree among themselves about redistributive ends. Consequently, economists fail to reach a consensus over the measure of distribution to place in the discipline's core. Unlike other people, many economists agree about redistributive means. Most economists who study law believe that redistributive goals can be accomplished better in modern states by progressive taxation than by reshuffling legal rights in such fields as torts, contracts, and crimes.

I can mention only a few of the reasons why economists believe that broadbased taxes are a better tool of redistribution than private or criminal law. ${ }^{8}$ First, redistributing a dollar from one group to another uses some of it. 
Redistribution by courts uses much more than redistribution by taxes. To illustrate, a plaintiff's attorney in the United States of America routinely charges one third of the judgment, whereas an accountant who prepares someone's income tax return charges a small fraction of the person's tax liability.

Second, redistribution by legal rights elicits more unproductive behaviour than redistribution by progressive taxation. People change their behaviour in unproductive ways to avoid the costs of redistribution and secure the benefits. To minimize unproductive responses, public finance economists urge the state to raise revenues from taxes with a broad base. Legal liability corresponds to a tax with a narrow base. To see why, assume that the state wishes to take income away from the owners of capital and given it to people with low income. The state could pursue this goal directly by taxing dividends. Alternatively, the state could pursue its goal indirectly through liability law. To be concrete, consider holding pharmaceutical companies absolutely liable for harmful side effects of medicinal drugs. Taxing dividends or holding pharmaceutical companies absolutely liable will cause people to change their behaviour in unproductive ways. To illustrate, taxing dividends will cause corporations to retain more profits, and pharmaceutical corporations will respond to absolute liability by refusing to market some drugs or by transferring production to partnerships. The principles of public finance predict that absolute liability of pharmaceutical companies will cause much larger, unproductive changes in behaviour than taxing dividends at the equivalent level. ${ }^{9}$

Third, the actual redistributive effects of adjusting legal rights may not be the anticipated effects. To illustrate, imagine that the state enacts a law imposing absolute liability on pharmaceutical companies in order to transfer wealth from stock holders to consumers. The legislators hope that increased tort awards will be paid by the owners of pharmaceutical stocks. In reality, the pharmaceutical companies may shift these costs to consumers by increasing the prices of drugs, rather than lowering dividends. ${ }^{10}$ In general, predicting the redistributive effects of liability law depends upon unraveling complex causal linkages.

Fourth, redistribution through legal rights may involve excessive 'leakage'. Leakage occurs when some rich people obtain part of the funds intended for redistribution to poor people. In general, leakage occurs because the law cannot exclude unintended beneficiaries. To illustrate, assume that drivers are richer than pedestrians on average. Noting this fact, lawmakers decide to redistribute income from the relatively rich to the relatively poor by holding drivers strictly liability for accidental harm to pedestrians. However, some cases will arise in which the pedestrian is wealthier than the motorist, in which case the liability rule will redistribute income from the relatively poor to the relatively rich. This problem arises because liability correlates imperfectly with income. 
These three basic concepts - maximization, equilibrium, and efficiency are fundamental to explaining behaviour in institutions that co-ordinate interactions among people. Nevertheless, critics of economic analysis doubt that these concepts can explain law. They ask, 'Isn't it better to describe psychology than to prescribe rationality?' 'Why stress equilibria instead of change?' 'Isn't the aim of law justice, not efficiency?' Quine observed that the core of a science consists of nearly tautological propositions. ${ }^{11} \mathrm{~A}$ tautology, such as 'All husbands are married', describes a convention about how to speak and reason. The core of economics is a formal mechanism of reasoning, with sufficient flexibility to generate alternative models. The alternative models may generate contradictory predictions. Testing contradictory predictions against facts confirms one model and disconfirms another. However, the core of economics, which generated both models, is not confirmed or disconfirmed.

Economists yawn when psychologists announce that empirical research shows that people do not compute their marginal costs and benefits. Like Quine, most economists believe that prediction occurs on the periphery of a science, not in the core. Critics who imagine that their observations disconfirm the core of economics have confused formality and reality. The core of economics should be praised or criticized according to its power to generate predictive models. The relevant question is whether more powerful models come from describing psychology rather than prescribing rationality, or stressing change rather than equilibria, or postulating that law aims for justice rather than efficiency.

Names that refer to some objects can be understood by pointing to them, such as saying 'cat' and pointing to a cat. Other concepts, like 'democracy', 'melody' or 'square root' cannot be conveyed by ostensive definition. Instead, mastering these terms typically involves practising their use, especially mathematical terms like 'square root'. Similarly, you cannot fully understand what economists mean by 'maximization' until you work through some maximizing models. Critics who have never worked through the models typically underestimate the flexibility of the core concepts of economics, rather like a person who knows the dictionary definition of a French word but cannot speak French. Before attacking the core concepts of the economic analysis of law, a critic should go through the intermediate step of understanding them.

Above the core and below the skin of an apple lies its meat. The meat of economics is a collection of concepts concerning what people maximize (selfinterest, profits, votes, and so on), the form of the equilibrium (perfect competition, monopoly, strategic, and so on), and the type of efficiency (Paretian, cost-benefit, utilitarian, and so on). In my opinion, the 'meat' of economics lacks some essential nutriments to nourish social science. Specifically, economics 'takes preferences as given' which means that it does not attempt 
to explain how people acquire their goals. Economics needs a theory of 'endogenous preferences' to explain how people decide what to maximize. The absence of such a theory keeps economics isolated from developmental psychology and theories of social reproduction.

In the next section, I suggest how to begin correcting this deficiency. Economists typically assume that a person pursues his or her self-interest as he or she perceives it. Whatever advances a person's goals serves his or her perceived self-interest. Consequently, self-interest presupposes personal goals, including the central values by which a person defines him or herself. A person acquires values by internalizing them. Internalized values are essential to morality and law. Economics offers no account of how internalization occurs. In other words, economics offers no account of how a person becomes the self in which he or she is interested. I will next discuss how economics might acquire such an account.

\section{THICK SELF-INTEREST ${ }^{12}$}

Max Weber argued that protestant Christians regard occupational choice as a religious calling, which causes people to internalize occupational roles. Internalization of occupational roles increases the dedication and creativity with which people pursue business goals. Dedication and creativity enable people to co-operate together in large organizations that apply technical knowledge and achieve scale economies. According to Weber, the protestant ethic brought the discipline of the monastery into the conduct of business, which perfected instrumental rationality as a mode of behaviour and created the industrial revolution. ${ }^{13}$

I restate Weber's claims in the language of modern economics. The need for many people to co-operate in a complex economy creates problems of information and motivation. For example, each employee in a large organization that applies science to production works under the direction of others and gets paid a fraction of the value that he co-operates in producing. The 'agency problem' is to design organizations and contracts to elicit effort and creativity from such workers. Eliciting effort and creativity requires aligning the self-interest of agents with the principal's interests. But, the narrow selfinterest of agents never aligns perfectly with the principal's interests. The agency problems become manageable in modern economies because people internalize occupational roles, which broadens their self-interest. When subordinates internalize occupational roles, they require less monitoring by superiors. Less monitoring lowers the transaction costs of contracting and managing hierarchies. Thus internalization of occupational roles is the ultimate form of decentralization, which prevents the constraints of information and motivation from strangling the modern economy.

Internalizing an occupational role involves accepting the norms of an occupation so intimately that they enter the individual's self-conception. As 
soon as an individual takes norms into his or her self-conception, he or she distinguishes two kinds of self-interest. The simplest self-interest, which I call 'thin self-interest', looks only to objective payoffs in wealth or power. The more complex self-interest, which I call 'thick self-interest', modifies objective payoffs to encompass the subjective value of morality. For example, many lawyers pursue power and wealth through their profession. In addition, some people aspire to be 'good lawyers', meaning people whose work embodies the virtues of the legal profession. The virtues of the profession include both its ethical standards and its technical craft.

Internalizing a role 'thickens' self-interest to include the obligations and goals of an occupation. Thus, the best workers express themselves by showing who they are through their work. Their work shows who they are by reflecting what they have internalized. Contemporary economics has nothing to say about self-expression through work. Self-expressive acts have meaning. The goals and feelings of the actor are the act's meanings for him. Thus, a theory of thick self-interest must be both a theory of behaviour and a theory of meaning. Economists often describe their subject as a 'behavioural science'. Other social sciences have recently returned to interpretivism and hermeneutics. The thick self provides a bridge between behavioural theory and theories of meaning.

\section{ENDOGENOUS PREFERENCES}

Psychologists have extensively studied the internalization of norms. Piaget, Kohlberg, and others sketched stages in the development of moral reasoning among children. ${ }^{14}$ According to their theories, a child perfects the ability to internalize norms as she or he acquires a capacity for abstract reasoning. Their research makes internalization sound cool and rational. In contrast, 'depth psychology' often traces internalization of morality to irrational processes that are hot and inchoate. According to these theories, internalization of morality ingrains new impulses in a child through emotional experiences. An example is Freud's theory of morality as the 'ghost in the nursery', meaning the repressed memory of parental punishments. ${ }^{15}$

Both types of internalization - accepting reasons and ingraining impulses - create new motives, which can tip the individual's motivational balance. Economic models often view motivation as a calculus of psychological benefits and costs. Internalization can change the sign of the net psychological benefits attached to an act. For example, internalization of morality creates subjective costs to non-co-operation that can shift the dominant strategy in a game from non-co-operation to co-operation. ${ }^{16}$ Internalization of norms changes preferences and decisively affects behaviour. However, economic theory cannot explain internalization or predict its occurrence. Filling this gap requires a theory of endogenous preferences linking economics and developmental psychology. A theory of endogenous 
preferences requires the expansion of decision theory to encompass the choice of who to become. Choosing among selves involves distinctive problems from choosing among commodities.

When self-interest thickens, conflicts arise between the thin and thick selves. For example, a lawyer may feel torn between being a 'good lawyer' and getting rich by shady means. Internal conflict, which is the subject of much psychology and moral philosophy, has only recently found a place in economic models. Economists usually assume that an actor chooses by ordering alternatives from better to worse. When modelling internal conflict, the actor chooses by drawing from a probability distribution over different orderings of the alternatives. One ordering might represent the thin self, the other ordering might represent the thick self, and the probability distribution might be determined by the actor's strength of will. ${ }^{17}$

\section{RATIONAL VERSUS REASONABLE}

The focus of economics on thin self-interest creates paradoxes, two of which I will discuss briefly. An independent judiciary is created by providing judges with life tenure, fixed salary, unpredictable promotion prospects, and the duty to remove themselves in cases affecting their material interest. The independence of the judiciary prevents judges from pursuing money, power or other aspects of narrow self-interest. Consequently, an unanswered question in the economic analysis of law is, 'What do independent judges maximize?' As long as economics focuses upon thin self-interest, this question is unanswerable. Instead of maximizing thin self-interest, independent judges typically express their own political and legal vision through their decisions. Their behaviour cannot be explained without a thick theory of a person's interests.

Similarly, voter participation rates in general elections cannot be explained by a thin theory of self-interest. As the number of voters increases, the probably that any one person's vote will influence the outcome of the election approaches zero. But, the opportunity cost of voting, in terms of time and effort, bears little or no relationship to the size of the jurisdiction. Therefore, a theory based upon narrow self-interest would predict much lower rates of voter turn-out in large jurisdictions than actually occurs in democracies. In reality, citizens vote in such elections to express their political preferences, not to gain material advantage. Consequently, the explanation of voting in large jurisdictions requires a thick theory of a person's interests.

The difference between thin and thick conceptions of self-interest relates to a fundamental tension between economics and law. The ideal economic decision maker is 'perfectly rational' which means utterly instrumental in pursuing explicit ends. The ideal legal decision maker is 'completely reasonable' which means that he or she has internalized social morality. The rational actor's self-conception is thin, whereas the reasonable actor's self- 
conception is thick. Without a thick conception of self-interest, economic analysis cannot answer important legal questions about reasonableness. Adjudicating the reasonableness of professional norms involves weighing the benefits and costs of internalization. For example, how far should a fiduciary go in subordinating his or her interest to the beneficiary's? As another example, most crimes cannot be committed accidentally or by the insane. These crimes presuppose criminal intent or 'mens rea'. To have criminal intent, the actor must know the difference between right and wrong, and choose to do wrong. The contribution of economics to understanding this problem will remain modest until decision theory encompasses psychological conflict between right and wrong.

\section{EVOLUTION OF NORMS}

Having discussed the internalization of norms by individuals, I will now discuss the evolution of norms in communities. The modern economy creates many specialized business communities, which may form around a technology, such as computer software, a body of knowledge, such as accounting, or a particular product, such as credit cards. Sociologists since Durkheim have tried to explain how the division of labour binds people together and facilitates co-operation, rather than fragmenting workers and promoting industrial strife. The answer concerns the way business communities generate norms. People develop relationships with each other through repeated interactions in a community, and norms arise to co-ordinate their interaction. The formality of the norms varies from one business to another. Self-regulating professions, like law and accounting, and formal networks like Visa, promulgate their own rules. Voluntary associations, like the Association of Home Appliance Manufacturers, issue guidelines. Informal networks, such as the computer software manufacturers, have inchoate ethical standards. (Elsewhere I refer to all such norms of business communities as the 'new law merchant'.)

Sociologists sometimes use 'norm' to mean 'typical' or 'modal' behaviour, but I use the term to mean 'obligatory behaviour'. For a community to have a customary norm, the obligation must achieve a minimum level of control over the behaviour of the community's members. Otherwise, the community does not have the customary norm in question. A customary norm affects behaviour when people internalize it. Internalizing a norm changes preferences in ways that I described as the 'thickening' of self-interest. Consequently, a customary norm emerges in a community when it is internalized by enough of its members.

Why do some games evoke a sense of obligation in the players concerning the strategies that they follow? I can only sketch an answer here. ${ }^{18}$ Imagine a sequential game involving two players and two moves. The first player invests or does not invest. Subsequently, the second player co-operates or 
appropriates. The first player will not invest unless he believes that the second player will co-operate. Therefore, the second player wants the first player to believe that she will co-operate, regardless of what she actually plans to do. Consequently, the second player will endeavour to signal 'co-operation'.

Now, embed this two-person game in a market with many participants. The participants consist of many 'first players' who want to invest, and many 'second players' who want to find an investor. All second players endeavour to signal 'co-operation'. Since everyone follows the same signalling strategy, the game has a 'pure signalling equilibrium'. A signal represents a player as following a particular strategy. A player who represents himself as following one strategy may actually follow another. Specifically, a player who represents herself as co-operating may actually appropriate. In a 'mixed equilibrium', some players co-operate and others appropriate. The people who co-operate form enduring relationships and secure a modest pay-off in most rounds of the game. The people who appropriate form temporary relationships (the investors exit immediately after appropriation) and secure a large pay-off in a few rounds of the game. Appropriators receive no pay-off in most rounds while they search for an investment partner. In equilibrium, both strategies earn the same average rate of return. ${ }^{19}$

More co-operation in the investment game will elicit more investment, which is productive and benefits all the players. Such external benefits, which all players enjoy, can be called 'local public goods'. Thus, the investment game has an equilibrium in which the players signal that they will supply a local public good. The community benefits from local public goods, so people concerned with its welfare will want to increase the supply. These people will say that everyone ought to co-operate. Saying that everyone ought to co-operate, including yourself, will become part of the way that a person signals necessary co-operation. As explained, everyone signals cooperation, including the appropriators. Consequently, a consensus will arise in the community that people who play the game ought to follow a cooperative strategy. This consensus will convince some people to internalize the obligation and inculcate it in young people. Thus a norm will arise. Generalizing, I formulate the alignment theorem: a social norm will evolve in a community when private incentives for signalling align with a local public good.

An interesting fact about the game, which I cannot explain here, concerns how internalizing the norm increases the supply of local public goods. People who internalize a norm typically cause the equilibrium to shift so that more people conform to it. However, the equilibrium does not shift because the person who internalizes the norm conforms to it. Rather, the equilibrium shifts because the individual who internalizes a norm typically becomes willing to enforce it on others. ${ }^{20}$

This account of the evolution of norms can address important questions in sociology, which I illustrate by two examples. First, consider LéviStrauss's application of Durkheim's ideas about social solidarity to tribes. 
Tribes expand the scope of co-operation by creating cross-cutting and overlapping systems of kinship. ${ }^{21}$ Kinship provides a framework for repeated interaction, which can be modelled as a repeated game. Repeated games enable co-operation, such as solving the prisoner's dilemma, whereas the corresponding one-shot game has a non-co-operative solution. Furthermore, repeated games often satisfy the conditions for the emergence of norms as specified above in the alignment theorem. Kinship and the state are substitutes in the sense that both provide a framework for co-operation and normativity.

Secondly, consider the domination of one group by another. Domination often results in economic exploitation. For example, the dominant group may form a cartel to suppress labour market competition from the subordinate group. By suppressing competition, the cartel can pay subordinate workers less than the competitive wage. Economic studies have long revealed the instability of cartels. Cartels are unstable because, while the cartel benefits all sellers as a whole, each individual member of the cartel gains an advantage from defecting. ${ }^{22}$ Norms backed by sanctions are required to prevent defection from cartels. This is true in business or social life. This is why domination typically requires support from internalized social norms, rather than being based upon pure power. For example, the domination of women by men probably requires most men and some women to believe in the rightness of patriarchy.

According to the theory of norms developed here, the group dominating ethical debate and moral education must sustain a consensus about the public good in order to stabilize its position. The account of norms developed here can help explain how the dominant social group can stabilize itself through the evolution of appropriate norms. Sustaining a consensus requires a game with a pure signalling equilibrium. The signalling equilibrium loses its purity when someone gains an advantage by signalling defection from the norm. Once the signalling equilibrium loses its purity, the norm may decay and the cartel may unwind. In these circumstances, the norms required to sustain domination will not persist spontaneously, so the dominant group cannot sustain its position without backing by state power.

Economists are often accused of ignoring social power, partly because no one has the power to affect prices in perfectly competitive markets. In general, game theory predicts how people act when they have the power to influence each other. A tension sometimes develops between the competitive market approach and game theory as economists increasingly analyse organizations and institutions. Tension develops because the competitive market approach emphasizes the optimality of private interaction, whereas game theory sometimes finds multiple, sub-optimal equilibria. Multiple equilibria inject arbitrariness into outcomes, and sub-optimal equilibria invite intervention by state authorities. To illustrate, the corporation can be regarded as a nexus of perfectly competitive contracts, in which case the state's proper role is to enforce the private contracts. Alternatively, the corporation can 
be regarded as a principal-agent game with market failures, ${ }^{23}$ in which case the state may impose regulations to correct the failures. As another example, the 'new utilitarians' like Ellickson see social norms as tending towards efficiency in small groups, whereas many feminists see social norms as tending towards subordination of women. ${ }^{24}$

\section{CONCLUSION}

I have suggested how to thicken the concept of self-interest in order to encompass the internalization of norms and the endogeneity of goals. Doing so will bring together economics and developmental psychology. I have also suggested now developing a theory of the evolution of norms based upon the positivist tradition in legal theory. Doing so will bring together economics and sociology.

Unification requires acknowledgment of core concepts used to explain all interactions. The concepts of maximization and equilibrium form part of the core of behavioural theory. While all social sciences should recognize the core of behavioural theory, each of the social sciences should retain its specialized theory. The assumption of exogenous preferences is special to economics. This assumption must be ejected from the core of unified social theory. In general, the unification of social science requires the separate disciplines to abandon their sovereignty, but not their identity. The model of unity is a federal system like the evolving European Community, not imperialism and not separate sovereignties.

\section{NOTES AND REFERENCES}

1 This section is based upon ch. 1 of R. Cooter and T. Ulen, Law and Economics (2nd ed., 1994).

2 W.M. Landes and R. Posner, 'The Influence of Economics on Law: A Quantitative Study' (1993) $36 \mathrm{~J}$. of Law and Economics 385-424.

3 R. Coase, 'The Problem of Social Cost' (1960) $3 \mathrm{~J}$. of Law and Economics 1.

4 D. Baird, R. Girtner, and R. Picker, Game Theory and the Law (1994).

5 This loose talk is hard to document. The study that I mentioned earlier found some indication of a slowing in the exponential growth of citations to articles applying economics to law. See Landes and Posner, op. cit., n. 2.

6 R.C. Ellickson, 'Bringing Culture and Human Frailty To Rational Actors: A Critique of Classical Law-and-Economics' (1989) 65 Chicago-Kent Law Rev. 23-55.

7 Hence the joke: Economist arrives at her office. A colleague asks, 'How's your husband?' She replies, 'Compared to what?'

8 For a model of why the state should not pursue distributional goals through civil law, see L. Kaplow and S. Shavell, The Efficiency of the Legal System versus the Income Tax in Redistributing Income (Harvard working paper no. 130, 1993).

9 The distortionary effect of a tax depends upon the taxed good's elasticity of supply and demand. The broader the base, the lower the elasticity. Drugs with harmful side effects for some people are a narrower base than dividends. Also note that dividends are a 
narrower base than income, which is why most economists prefer for the state to raise money by a tax on all income. To keep the comparison fair, we must compare taxes on different bases that raise the same amount of revenue for the state. The phrase 'at the equivalent level' refers to the level that raises equivalent amounts of money for redistribution. For an exposition of the principles of public finance, see $P$. Musgrave and R. Musgrave, Public Finance in Theory and Practice (1976).

10 Note that capital must earn the same rate of return in all forms of investment in the long run, so consumers will assuredly pay for higher liability awards against companies through higher prices for products in the long run.

11 W. von Quine, 'Two Dogmas of Empiricism' in From a Logical Point of View (1953) 20-46.

12 This section is based upon my lecture, 'Prices and Obligations' at the Seminar D'Actualitat Juredica: 'Dret, Economia i Empresa Juridica', Justice Department of Catalonia, Barcelona, 17 March 1994.

13 M. Weber, The Protestant Ethic and the Spirit of Capitalism, tr. T. Parsons (2nd ed., 1976).

14 L. Kohlberg, 'Moral Stages and Moralization: The Cognitive-Developmental Approach' in Moral Development and Behavior: Theory, Research, and Social Issues, ed. T. Lickona (1976) 31-53; L. Kohlberg, 'Stage and Sequence: The Cognitive-Development Approach to Socialization' in Handbook of Socialization Theory and Research, ed. D.A. Goslin (1969); L. Kohlberg, The Philosophy of Moral Development: Moral Stages and the Idea of Justice (1981); L. Kohlberg, 'Appendix. The Six Stages of Moral Judgment' in The Philosophy of Moral Development: Essays on Moral Development, vol. I (1981) 409-12. Flaws in Kohlberg's approach have generated much criticism from feminists, notably Carol Gilligan, In a Different Voice: The Psychology of Women's Development (1982) 8 and 16-17.

15 In Freud's account, morality is the repressed memory of punishment and threats from the father. In technical terms, the super-ego emerges when the child represses his Oedipal fears. See S. Freud, The Ego and the Id (1962), tr. J. Riviere, revised and edited by J. Strachey. A clear discussion of these ideas is provided by R. Wollheim in 'The Last Phase', ch. 7 of his Sigmund Freud (1971).

16 See R. Cooter, 'Structural Adjudication and the New Law Merchant: A Model of Decentralized Law' (1994) 14 International Rev. of Law and Economics 215-31.

17 A model with citations is found in R. Cooter, 'Lapses, Conflict, and Akrasia in Torts and Crimes: Towards An Economic Theory of the Will' (1991) 11 International Rev. of Law and Economics 149-64.

18 For a more complete development of this game, see Cooter, op. cit., n. 16.

19 By definition, an evolutionary equilibrium exists when all strategies actively played earn the same average rate of return.

20 In equilibrium, the strategy of conforming to the norm receives the same expected payoff as the strategy of violating it. Consequently, a person who stops violating the norm and starts conforming to it will cause someone else to stop conforming and start violating. The net effect is nil. However, a person who starts punishing other people who violate the norm will cause the expected pay-off to fall for violators. To restore an equal expected rate of return to violators and conformers, the number of violators must fall.

21 A good review of how Lévi-Strauss extended Durkheimian ideas of social solidarity to kinship is in M. Harris, The Rise of Anthropological Theory (1968).

22 To illustrate, the oil-producing nations benefitted as a whole from a cartelized world price for oil, but each individual oil producing nation benefitted even more from secretly discounting oil prices below the level set by the cartel. Individual nations benefit from offering secret discounts because the volume of their sales soars. Consequently, the OPEC cartel unravelled.

23 To contrast these two theories, see L.A. Bebchuk (ed.), Corporate Law and Economic Analysis (1990): for example, contrast F. Easterbrook and Daniel R. Fischel, 'The corporate contract' pp. 182-215 with H. Hansmann, 'Ownership of the firm' pp. 281-313.

24 R.C. Ellickson, Order Without Law: How Neighbors Settle Disputes (1991). 